\title{
Fuzzy expert systems: an application to short-term load forecasting
}

\author{
Y.-Y. Hsu \\ K.-L. Ho
}

\begin{abstract}
An expert system using fuzzy set theory is presented for short-term load forecasting. Since most statistical methods for short-term load forecasting rely heavily on weather variables and statistical models, errors may appear in the forecasted hourly loads due to uncertainties in weather variables and statistical models. Thus, to have better accuracy, the operators in many utilities try to update the forecasted loads in real time using the records of the past few hours and their heuristic rules. In the paper, an expert system to perform this updating function is developed. Experienced operators' heuristic rules are imbedded in the knowledge base. The uncertainties in weather variables and statistical models are dealt with using the fuzzy-set theory. To demonstrate the effectiveness of the proposed fuzzy expert system, short-term load forecasting is performed on the Taiwan power system. Test results indicate that the fuzzy expert system is very effective in improving the accuracy of the forecast hourly loads.
\end{abstract}

\section{Introduction}

Short-term load forecasting is important in online scheduling of a utility [1]. Many statistical methods such as exponential smoothing [2], multiple regression [3-5], Box-Jenkins [6], and Kalman filter [7] have been proposed for short-term load forecasting. To take the operators' experience and heuristic rules into account, applications of expert systems have also been reported $[8,9]$.

In a recent book [10], an expert system was designed by the authors for load forecasting at the Taiwan Power Company (TPC). In the development of that expert system, it was observed that the most important factors that affect load-forecast accuracy are daily load patterns and daily load peaks and troughs. To have precise load patterns, as many as ten different day types have been identified from operators' experience and the load data in the database of TPC. Weather-sensitive models have been used for peak-load and trough-load forecasting. Application of the expert system to load forecasting of TPC gives a yearly mean absolute error (MAE) of $2.38 \%$. This is a rather promising result.

After the success in the first phase of the work, the

Paper 9057C (P9), received 9th September 1991

The authors are with the Department of Electrical Engineering, National Taiwan University, Taipei, Taiwan, Republic of China operators in TPC suggest that the accuracy of the forecast hourly loads can be further improved if the loads are updated every one hour or few hours. The main reason for the operators to carry out the updating is that the forecast hourly loads depend on forecast peak and trough loads which, in turn, rely heavily on weather variables (temperature, humidity etc.) and there always exist a certain amount of errors in the forecasted weather variables. Thus, the uncertainties in the weather variables will result in errors in the peak and trough loads and the final hourly loads. To see how the peak and trough loads affect the load forecast results, Table 1 compares the forecast errors [MAE and root-mean-square error (RMSE)] by using the actual peak and trough loads and by using the forecast peak and trough loads. It is observed that the yearly MAE can be reduced from $2.38 \%$ to $1.20 \%$ if the actual peak and trough loads are employed for load forecasting.

Table 1: Comparison of forecast results using actual and forecast peak and trough loads

\begin{tabular}{lll}
\hline & $\begin{array}{l}\text { Using actual peak } \\
\text { and trough loads }\end{array}$ & $\begin{array}{l}\text { Using forecasted peak } \\
\text { and trough loads }\end{array}$ \\
\hline MAE & $1.20 \%$ & $2.38 \%$ \\
RMSE & $1.56 \%$ & $2.75 \%$ \\
\hline
\end{tabular}

In practice, it is impossible for the operators to have the actual peak and trough loads in real-time applications. However, the operators can compare the actual weather variables with the forecast weather variables for the past few hours and use their experience to update the forecast peak load and trough load to make them close to actual values. Then the accuracy of the forecast hourly loads can be improved.

In view of the need to update peak and trough loads using uncertain weather variables, it is desirable to design an expert system which is capable of dealing with uncertain informations and heuristic rules. In the literature, certainty factors [11], Dempster-Shafer theory of evidence [12] and fuzzy-set theory [13-14] have been proposed to manage uncertainty in expert systems. In this paper, fuzzy set approach has been adopted for expertsystem design. To put together separate fuzzy information to reach the desired change in peak load and trough load, a minimum-maximum algorithm and an equal-area algorithm are presented. To demonstrate the effectiveness of the proposed fuzzy expert system, load forecasting has been performed on Taiwan power system. It is found that the MAE can be significantly reduced by the fuzzy expert system.

In Section 2, fuzzy set theory is briefly described. This is followed by the design of a fuzzy expert system for load 
forecasting. An example is then given to demonstrate the effectiveness of the expert system.

\section{$2 \quad$ Fuzzy set theory}

In the past two decades, several interesting applications of the fuzzy set theory have been reported in the areas of expert systems, operational research, control engineering and others. Before going into the details of fuzzy-expertsystem design, some basic definitions and mathematical operations of fuzzy sets are described as follows [13]

\subsection{Definition of a fuzzy set}

Definition 1: Fuzzy set: Let $X$ be a collection of objects ( $X$ is the universal set); then a fuzzy set $A$ in $X$ is defined to be a set of ordered pairs:

$$
A=\left\{\left[x, \mu_{A}(x)\right] \mid x \in X\right\}
$$

where $\mu_{A}(x)$ is called the membership function of $x$ in $A$.

Note that the membership function $\mu_{A}(x)$ denotes the degree that $x$ belongs to $A$ and is normally limited to values between 0 and 1 . A high value of $\mu_{A}(x)$ implies that it is very likely for $x$ to be in $A$. Elements with a zero degree of membership are normally not listed. If we limit the values of the membership function to be either 0 or 1 , then A becomes a crisp (nonfuzzy) set.

\subsection{Fuzzy set operations}

Some important operations with fuzzy sets which will be used later are defined via their membership functions.

Definition 2: The union of two fuzzy sets: Let $A$ and $B$ be two fuzzy sets with membership functions $\mu_{A}(x)$ and $\mu_{B}(x)$, respectively. The membership function of the union $C=A \cup B$ is point-wise defined by

$$
\mu_{C}(x)=\max \left\{\mu_{A}(x), \mu_{B}(x)\right\} x \in X
$$

Definition 3: The intersection of two fuzzy sets: Let $A$ and $B$ be two fuzzy sets with membership functions $\mu_{A}(x)$ and $\mu_{B}(x)$, respectively. The membership function of the intersection $D=A \cap B$ is defined by

$$
\mu_{D}(x)=\min \left\{\mu_{A}(x), \mu_{B}(x)\right\} x \in X
$$

Definition 4: Let $A$ and $B$ be two fuzzy sets with membership functions $\mu_{A}(x)$ and $\mu_{B}(x)$, respectively. The membership function of the sum $S=A+B$ is defined by

$$
\mu_{S}(z)=\sup _{z=x+y} \min \left\{\mu_{A}(x), \mu_{B}(y)\right\}
$$

\section{Design of the fuzzy expert system}

\subsection{Crisp expert system}

Before the details of fuzzy-expert-system design are presented, the procedures for load forecasting in the crisp expert system [10] are summarised.

Step 1: Read in the day to be forecast and the forecast weather variables.

Step 2: Identify day type and get the 24 normalised hourly loads $L_{n}(i), i=1,2, \ldots, 24$, for that particular day type. These normalised hourly loads have been stored in the database of the expert system to represent the load pattern of each day type.

Step 3: Compute the forecast daily peak load and trough load using the equations

$$
\begin{aligned}
& L_{p}=g_{p} * T_{p}+h_{p} \\
& L_{t}=g_{t} * T_{t}+h_{t}
\end{aligned}
$$

where

$L_{p}=$ peak load of the day,

$L_{\mathrm{t}}=$ trough load of the day,

$T_{p}=$ equivalent forecast high temperature of the system on the day,

$T_{t}=$ equivalent forecast low temperature of the system on the day, $g_{p}, h_{p}, g_{t}$ and $h_{t}$ are coefficients determined by least-square-error technique using the load and weather data in the database of TPC.

Step 4: Compute the forecast hourly loads $L(i)$ as follows:

$$
L(i)=L_{n}(i)\left(L_{p}-L_{t}\right)+L_{t} \quad i=1,2, \ldots, 24
$$

Details of these procedures are given in Reference 10 .

\subsection{Fuzzy expert system}

It is observed from eqn. 7 that the forecast hourly loads depend on both the load pattern $L_{n}(i)$ and the forecast peak load $L_{p}$ and trough load $L_{t}$. It has been mentioned that our main purpose is to update the peak and trough loads in order to achieve better results.

From eqns. 5 and 6 , it is obvious that the peak load and trough load are expressed as linear functions of the forecast high temperatures and low temperatures, respectively. Two kinds of uncertainties arise from this peakload- and trough-load forecasting process, i.e. the uncertainty in the statistical model and the uncertainty in forecast temperatures. The reason for the uncertainties and the proposed methods to deal with the uncertainties are described as follows.

\subsubsection{Uncertainty in statistical model}

The coefficients $g_{p}, h_{p}, g_{t}$ and $h_{t}$ for peak-load and toughload forecasting are determined by using the least-squareerror approach. Fig. 1 depicts the historical data of peak loads and temperatures for ten weekdays in August 1987. Also shown in the Figure is a linear-regression curve obtained by the least-square-error method. It is observed that the data points spread over the vicinity of the regression curve and there exists an error between each sample point and the regression line. This is called the statistical modeling error and will cause errors in the resulting peak and trough loads even if the forecast temperature is accurate.

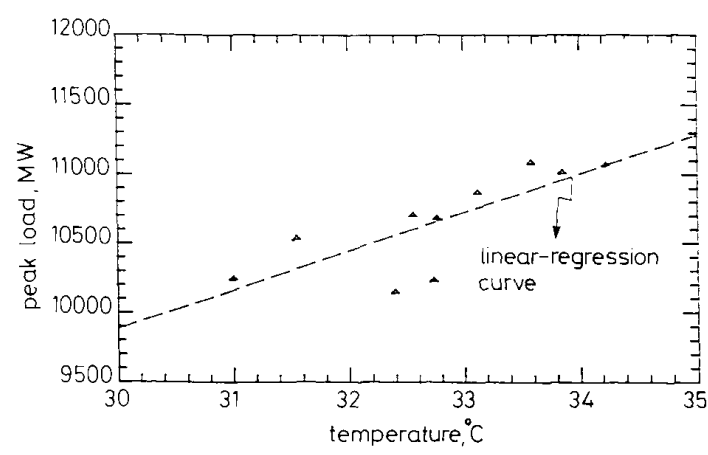

Fig. 1 Historical data of peak loads and temperatures

In view of the error in the statistical model, it is desirable to add an error term to the equations for peak-load and trough-load forecasting. Thus, eqn. 5 and eqn. 6 become

$$
\begin{aligned}
& L_{p}=g_{p} * T_{p}+h_{p}+\varepsilon_{p} \\
& L_{t}=g_{t} * T_{t}+h_{t}+\varepsilon_{t}
\end{aligned}
$$


where the uncertain-error terms $\varepsilon_{p}$ and $\varepsilon_{\mathrm{r}}$ are treated as fuzzy numbers. Fig. 2 depicts the membership function of $\varepsilon_{p}$ for a certain day type. It is observed that the value of the membership function is 1 for $\varepsilon_{p}=0$ and decreases to

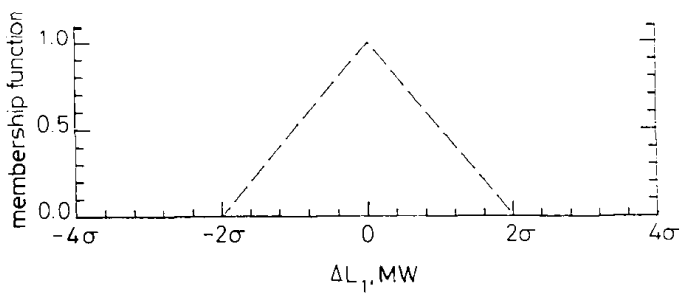

Fig. 2 Membership function for the change in peak load due to statistical-model uncertainty

0 at $\varepsilon_{p}=2 \sigma$, where $\sigma$ is root-mean-square error between the sample points and the linear-regression curve and is computed from the historical data as follows:

$$
\sigma=\left\{\sum_{i=1}^{n}\left(L_{p i}-g_{p} * T_{p i}-h_{p}\right)^{2} / n\right\}^{1 / 2}
$$

where $n$ is the number of sample points in the database for that particular day type and $L_{p i}$ and $T_{p i}$ are the peak load and high temperature for the $i$ th sample points, respectively. The membership function of $\varepsilon_{t}$ can be derived in the same way using the historical data of trough loads and low temperatures.

Thus, the membership function for the change in peak (trough) load due to statisical-model uncertainty can be written as

$$
F_{1}\left(\Delta L_{1}\right) \begin{cases}=1-0.5 * \operatorname{abs}\left(\Delta L_{1} / \sigma\right) & \text { for }\left|\Delta L_{1}\right| \leqslant 2 \sigma \\ =0 & \text { elsewhere }\end{cases}
$$

Note that $\Delta L_{1}$ in eqn. 11 could be either $\varepsilon_{p}$ or $\varepsilon_{t}$, depending on whether peak load or trough load is to be updated.

\subsubsection{Uncertainty in forecast temperatures}

Since there always exist errors in the forecast temperatures, the operators must trace temperature readings either from the Central Weather Bureau or from the utility-substation meters to see if the actual temperatures deviate too much from the forecast values. If so, certain action must be taken to update the forecast temperatures and hence the forecast peak and trough loads. It is the experience of TPC operators that the temperature error is less than $4^{\circ} \mathrm{C}$ in most cases. Therefore, in the proposed fuzzy expert system, the users are asked to select one among the following options:

(i) The temperature is much lower (ML) than the forecast value.

(ii) The temperature is lower (L) than the forecast value.

(iii) The temperature is close (C) to the forecast value.

(iv) The temperature is higher $(\mathrm{H})$ than the forecast value.

(v) The temperature is much higher $(\mathrm{MH})$ than the forecast value.

The membership functions for these options can be expressed as

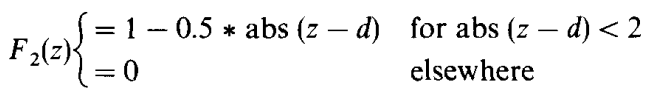

where $z=$ error in the forecast (high or low) temperature, $F_{2}(z)=$ the membership function for a temperature error $z$, and $d=-4$ for option $1(\mathrm{ML}),-2$ for option 2 (L) $=0$ for option $3(\mathrm{C}),=2$ for option $4(\mathrm{H})$ or $=4$ for option 5 (MH).

It is observed from eqns. 8 and 9 that an error in temperature will result in a proportional error in peak (or trough) load. The membership function for the change in peak (trough) load due to the error in forecast temperatures can therefore be described by

$$
F_{2}\left(\Delta L_{2}\right) \begin{cases}=1 & -0.5 * \operatorname{abs}\left(\Delta L_{2}-g d\right) \\ & \text { for abs }\left(\Delta L_{2}-g d\right)<2 g \\ =0 \quad & \text { elsewhere }\end{cases}
$$

where $\Delta L_{2}=$ change in peak (trough) load, and $g=g_{p}$ for peak-load forecasting and $g_{t}$ for trough-load forecasting.

These membership functions are depicted in Fig. 3.

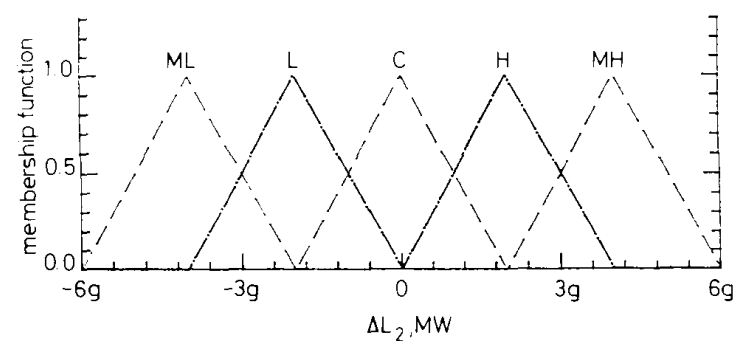

Fig. 3 Membership functions for the change in peak (trough) load due to error in forecast temperatures

\subsubsection{Combination of statistical-model uncertainty and forecast-temperature uncertainty}

Taking both the uncertainty in the statistical model and that in forecasted temperatures into account, the peak (trough) load should be updated by an amount

$$
\Delta L_{3}=\Delta L_{1}+\Delta L_{2}
$$

The membership function for $\Delta L_{3}$ can be found by using eqns. 4,11 , and 13 .

$$
F_{3}\left(\Delta L_{3}\right)=\sup _{\Delta L_{3}=\Delta L_{1}+\Delta L_{2}} \min \left[F_{1}\left(\Delta L_{1}\right), F_{2}\left(\Delta L_{2}\right)\right]
$$

\subsubsection{Operators' heuristic rules}

In addition to the two fuzzy models described so far, a third model based on operators' experience will be derived for peak-(trough-) load updating. Since the operators can use their experience to update the forecast loads in real-time applications, it is crucial for the expert system to use experienced operators' heuristic rules to modify the peak (trough) load. Our approach begins with asking the operator how much he would like to modify the peak (trough) load and his degree of confidence in the suggested load change. Previous operating experience suggested that the amount of load change should be within the range from $\pm 1500 \mathrm{MW}$. It was also recommended that three confidence levels be used for load updating. The operators can be quite confident, confident, or not confident with the suggested amount of load change. Thus the membership function for the operators' suggested load change can be written as

$$
F_{4}\left(\Delta L_{4}\right) \begin{cases}=1-\operatorname{abs}\left(\Delta L_{4}-x\right) / y \\ \quad & \text { for abs }\left(\Delta L_{4}-x\right)<y \\ =0 \quad & \text { elsewhere }\end{cases}
$$

where $F_{4}=$ the membership function for a load change $\Delta L_{4}, x=$ the operator's recommended amount of load 
change, $y=250 * 0.8$ if the operator is 'quite confident' about the recommended load change, 250 if the operator is 'confident' about the recommended load change or $250 / 0.8$, if the operator is 'not confident' about the recommended load change.

Note that the values of $y$ have been chosen based on the observation that a load-forecasting error of 200 $300 \mathrm{MW}$ can be achieved be experienced operators via real-time updating.

Example 1: Fuzzy sets for operators' update of forecast load: To demonstrate the use of fuzzy models in the operators' recommended load change, consider the case where the operator responds to the expert system with a load change of $-250 \mathrm{MW}$. If the level of confidence is 'quite confident', then the fuzzy set describing the amount of load change is given by

$$
\begin{aligned}
\left\{\left[\Delta L_{4}, F_{4}\left(\Delta L_{4}\right)\right]\right\} & =\{(-400,0.25),(-350,0.5),(-300,0.75) \\
& (-250,1),(-200,0.75),(-150,0.5) \\
& (-100,0.25)\}
\end{aligned}
$$

Note that only those values of load change which are multiples of 50 are explicitly shown in eqn. 17. The actual membership function can be represented by two line segments as shown in Fig. 4.

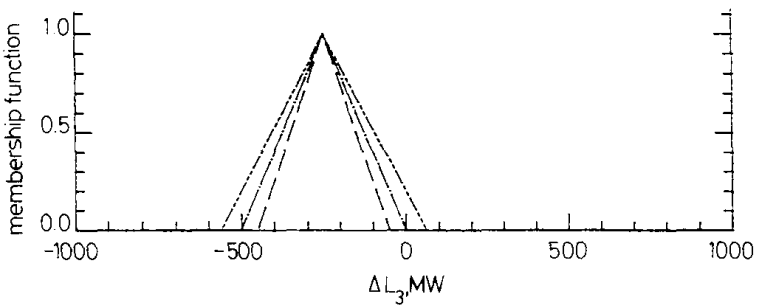

Fig. 4 Membership function of example 1

-... quite confiden

$\begin{array}{ll}-\cdot \cdot \cdot & \text { confident } \\ -\cdot \cdot \cdot \cdot- & \text { not confiden }\end{array}$ by

If the operator is 'confident', then the fuzzy set is given

$$
\begin{aligned}
& \{(-450,0.2),(-400,0.4),(-350,0.6) \\
& (-300,0.8),(-250,1),(-200,0.8) \\
& (-150,0.6),(-100,0.4),(-50,0.2)\}
\end{aligned}
$$

If the operator is 'not confident', then the fuzzy set is given by

$$
\begin{aligned}
& \{(-550,0.04),(-500,0.2),(-450,0.36) \\
& (-400,0.52),(-350,0.68),(-300,0.84) \\
& (-250,1),(-200,0.84),(-150,0.68) \\
& (-100,0.52),(-50,0.36),(0,0.2),(50,0.04)\}
\end{aligned}
$$

It is obvious from Fig. 4 that the more confident is the operator with his recommendation, the steeper will be the line segments of the membership function. In other words, all possible values of load change will be very close to the value suggested by the operator if he is "quite confident' with the answer.

\subsubsection{Update the peak (trough) load}

We now have two separate pieces of information on the amount that the peak (trough) load should be changed: the load change $\Delta L_{3}$ derived from statistical model and the load change $\Delta L_{4}$ recommended by the operators. Our purpose is to determine the most desirable load change $\Delta L_{\text {desired }}$ from the membership functions $F_{3}\left(\Delta L_{3}\right)$ and $F_{4}\left(\Delta L_{4}\right)$ and update the peak (trough) load using the equations

$$
\begin{aligned}
& L_{p \text { updated }}=L_{p \text { forecast }}+\Delta L_{p \text { desired }} \\
& L_{t \text { updated }}=L_{t \text { forecast }}+\Delta L_{t \text { desired }}
\end{aligned}
$$

where

$$
\begin{aligned}
L_{p \text { forecast }}, L_{t \text { forecast }}= & \text { forecast peak (trough) load } \\
L_{p \text { updated }}, L_{t \text { updated }} & =\text { updated peak (trough) load } \\
\Delta L_{p \text { desired }}, \Delta L_{t \text { desired }}= & \text { desired change in peak (trough) } \\
& \text { load }
\end{aligned}
$$

Among the various approaches for determining the desired change in peak (trough) load, the minimummaximum algorithm and the equal-area algorithm are most commonly used and will be briefly described as follows.

Minimum-maximum algorithm: In the minimummaximum approach, the desirable load change in peak (trough) load is given by

$$
\begin{aligned}
\Delta L_{\text {desired }}= & \text { the value of } \Delta L \text { which gives maximum } \\
& \text { value of } F(\Delta L)
\end{aligned}
$$

where $\Delta L_{\text {desired }}$ and $\Delta L$ can be either peak-load change or trough-load change and $F(\Delta L)$ is expressed as

$$
F(\Delta L)=\min \left\{F_{3}(\Delta L), F_{4}(\Delta L)\right\}
$$

Example 2: Consider the case described in example 1 . The membership function $F_{4}\left(\Delta L_{4}\right)$ for the case where the operator is 'not confident' with the recommended load change is repeated in Fig. 5. Also shown in Fig. 5 is a typical membership function for $F_{3}(\Delta L)$. Using the two membership functions, $F(\Delta L)$ and $\Delta L_{\text {desired }}$ can be found.

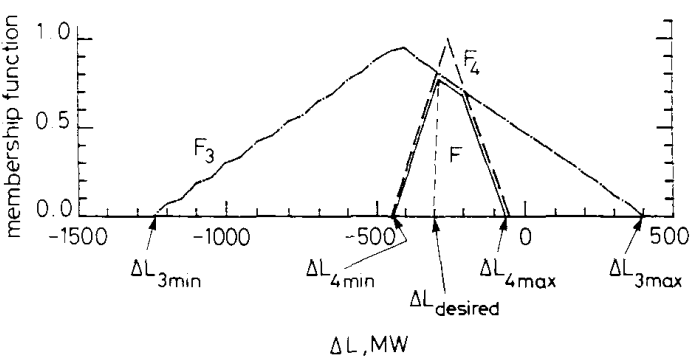

Fig. 5 Minimum-maximum algorithm

Equal-area algorithm: The equal-area method is best explained by an example.

Example 3: Consider again the membership functions $F_{3}(\Delta L)$ and $F_{4}(\Delta L)$ in Fig. 5. The equal-area algorithm proceeds as follows.

Step 1: Ask the operator about the weighting factors he would place on $\Delta L_{4}$ (operator's recommendation) and on $\Delta L_{3}$ (statistical model). Let the ratio of the two weighting factors be $W$.

Step 2: As shown in Fig. 6, the maximum value of $F_{4}(\Delta L)$ is changed from 1 [the maximum value of $F_{4}(\Delta L)$ in Fig. 5] to a new value $F_{4 \text {, peak }}^{\prime}$ such that

$$
\frac{A_{4}}{A_{3}}=W
$$


where $A_{4}=$ the area under the updated $F_{4}(\Delta L)$ curve and $A_{3}=$ the area under the $F_{3}(\Delta L)$ curve.

Note that the $F_{3}(\Delta L)$ curve in Fig. 6 is the same as that in Fig. 5. It is also observed that $\Delta L_{4 \min }$ and $\Delta L_{4 \max }$ in Fig. 6 are the same as those in Fig. 5.

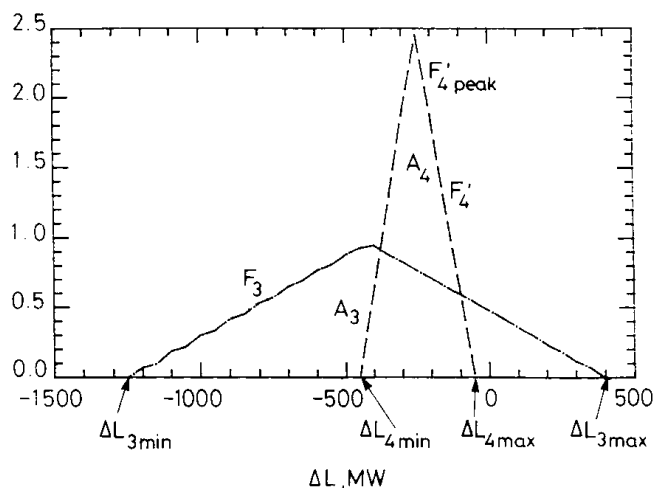

Fig. 6 Equal-area algorithm

Step 3: Define

$$
A(\Delta L)=\int_{\Delta L_{3 \text { min }}}^{\Delta L}\left\{F_{3}(x)+F_{4}^{\prime}(x)\right\} d x
$$

for $\Delta L>\Delta L_{3 \text { min }}$

Then the sum of the areas under the membershipfunction curves $F_{3}$ and $F_{4}^{\prime}$ is given by

$$
A_{\text {total }}=A\left(\Delta L_{3 \max }\right)
$$

The equal-area method states that the desired load change $\Delta L_{\text {desired }}$ can be reached by solving the equation

$$
A\left(\Delta L_{\text {desired }}\right)=\frac{1}{2} A_{\text {total }}
$$

Fig. 7 shows the curve $A(\Delta L)$ and the resultant $\Delta L_{\text {desired }}$ for the membership functions $F_{3}$ and $F_{4}$ in Fig. 6.

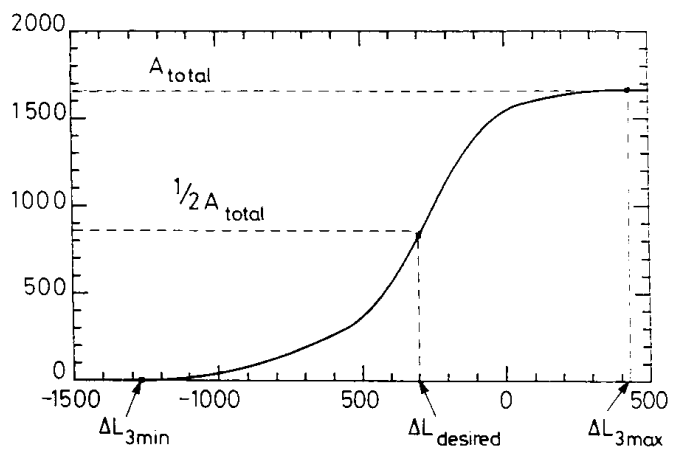

$\Delta L, M W$

Fig. 7 Curve $A(\Delta L)$ for the membership functions $F_{3}$ and $F_{4}$

\section{Results}

To demonstrate the effectiveness of the proposed expert system, load forecasting is performed on Taiwan power system using both the crisp expert system and the fuzzy expert system. Table 2 gives the forecast results for a typical day (13 August, 1987) using the crisp expert system proposed in Reference 10 . It is observed that the MAE is $1.89 \%$ and the errors in peak load and trough load are $265.87 \mathrm{MW}(2.45 \%)$ and $97.99 \mathrm{MW}(0.90 \%)$, respectively.
Table 2: Forecast hourly loads using the crisp expert system

\begin{tabular}{rcrrr} 
Hour & $\begin{array}{l}\text { Actual } \\
\text { loads }(\mathrm{MW})\end{array}$ & $\begin{array}{l}\text { Forecast } \\
\text { loads }(\mathrm{MW})\end{array}$ & Error $(\mathrm{MW})$ & Error $(\%)$ \\
\hline 1 & 7589.0 & 7652.17 & -63.17 & $-5.82 \mathrm{E}-03$ \\
2 & 7277.00 & 7346.42 & -69.42 & $-6.40 \mathrm{E}-03$ \\
3 & 7101.00 & 7131.07 & -30.08 & $-2.77 \mathrm{E}-03$ \\
4 & 6892.00 & 6968.88 & -76.88 & $-7.09 \mathrm{E}-03$ \\
5 & 6763.00 & 6837.35 & -74.35 & $-6.85 \mathrm{E}-03$ \\
6 & 6681.00 & 6781.33 & -100.33 & $-9.25 \mathrm{E}-03$ \\
7 & 6670.00 & 6767.99 & -97.99 & $-9.03 \mathrm{E}-03$ \\
8 & 7242.00 & 7387.45 & -145.45 & $-1.34 \mathrm{E}-02$ \\
9 & 9333.00 & 9471.06 & -138.06 & $-1.27 \mathrm{E}-02$ \\
10 & 10068.0 & 10178.52 & -110.52 & $-1.02 \mathrm{E}-02$ \\
11 & 10393.00 & 10673.40 & -280.40 & $-2.58 \mathrm{E}-02$ \\
12 & 10483.00 & 10801.93 & -318.93 & $-2.94 \mathrm{E}-02$ \\
13 & 9384.00 & 9581.79 & -197.79 & $-1.82 \mathrm{E}-02$ \\
14 & 10710.00 & 10921.98 & -211.98 & $-1.95 \mathrm{E}-02$ \\
15 & 10848.00 & 11113.87 & -265.87 & $-2.45 \mathrm{E}-02$ \\
16 & 10658.00 & 10961.24 & -303.24 & $-2.80 \mathrm{E}-02$ \\
17 & 10421.00 & 10787.47 & -366.47 & $-3.38 \mathrm{E}-02$ \\
18 & 9587.00 & 9939.75 & -352.75 & $-3.25 \mathrm{E}-02$ \\
19 & 9576.00 & 9832.97 & -256.97 & $-2.37 \mathrm{E}-02$ \\
20 & 9822.00 & 10121.74 & -299.74 & $-2.76 \mathrm{E}-02$ \\
21 & 9538.00 & 9878.16 & -340.16 & $-3.14 \mathrm{E}-02$ \\
22 & 9037.00 & 9364.90 & -327.90 & $-3.02 \mathrm{E}-02$ \\
23 & 8696.00 & 8979.09 & -283.09 & $-2.61 \mathrm{E}-02$ \\
24 & 8221.00 & 8432.23 & -211.23 & $-1.95 \mathrm{E}-02$ \\
\hline
\end{tabular}

MAE $=1.89 \%, \quad$ RMSE $=2.13 \%$, forecast peak $=11113.87 \mathrm{MW}$ actual peak $=10848 \mathrm{MW}$, error $=-265.87 \mathrm{MW}(-2.45 \%)$, forecast trough $=6767.99 \mathrm{MW}, \quad$ actual trough $=6670 \mathrm{MW}, \quad$ error $=$ $-97.99 \mathrm{MW}(-0.90 \%)$

To reduce the error in peak-load forecasting and improve the accuracy in forecast hourly loads, the proposed fuzzy expert system is also tested. As shown in Fig. 8 , the expert system begins with asking the user how much he wants to change the peak load and how much he thinks the actual high temperature is away from the forecast value.

Please answer the following questions:

(A) How much do you want to change the peak load $(-1500 \mathrm{MW}$ to $1500 \mathrm{MW}):-250$

(B) Are you

1. Quite confident

2. Confident

3. Not confident

with the suggested load change?

Choose: 3

(C) The actual high temperature will be

1. Much lower that the forecast value

2. Lower than the forecast value

3. Close to the forecast value

4. Higher than the forecast value

5. Much higher than the forecast value

Choose: 2

The suggested peak load is : $10813.87 \mathrm{MW}$

Fig. 8 Query from the fuzzy expert system

After the user responds to the questions, the expert system calculates the membership functions $F_{1}(\Delta L)$, $F_{2}(\Delta L)$ and $F_{3}(\Delta L)$ for peak-load updating using eqns. 11,13 and 15. The results are depicted in Fig. 9. The membership function $F_{4}(\Delta L)$ has been given in Fig. 4 . For convenience, these four membership functions are also tabulated in Table 3 using an increment of $50 \mathrm{MW}$. Since the membership functions $F_{3}\left(\Delta L_{3}\right)$ and $F_{4}\left(\Delta L_{4}\right)$ in Fig. 5 are indeed the functions for the present case, it can be observed from Fig. 5 that the desired change in peak load $\Delta L_{p \text { desired }}$ is $-296 \mathrm{MW}$ if the maximum-maximum algorithm is employed. On the other hand, as evidenced by Fig. 6 and Fig. 7, a value of $-298 \mathrm{MW}$ will be 
reached for $\Delta L_{p \text { desired }}$ if the equal-area algorithm is used. Note that both approaches will yield the same value of $\Delta L_{p \text { desired }}(-300 \mathrm{MW})$ if a discrete-fuzzy-set representation with an increment of $50 \mathrm{MW}$ as shown in Table 3 is employed. But this is a pure coincidence. In general, the

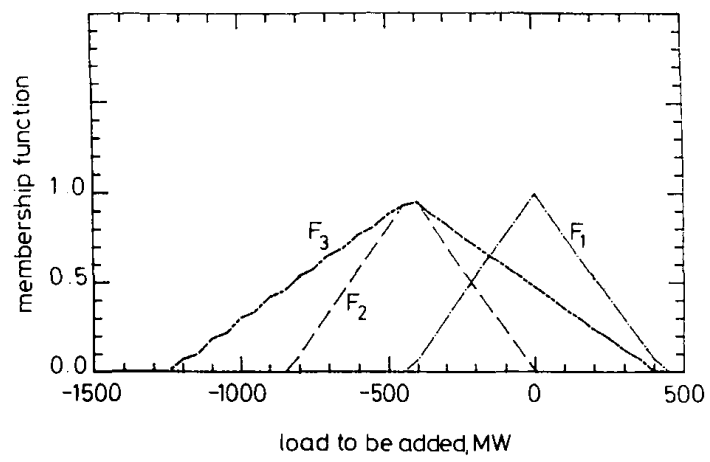

Fig. 9 Membership functions $F_{1}, F_{2}$ and $F_{3}$ for peak-load updating

Table 3: Fuzzy sets for peak-load updating $(W=2.45)$

\begin{tabular}{lllll}
\hline $\begin{array}{l}\text { Load } \\
\text { change }\end{array}$ & $F 1$ & $F 2$ & $F 3$ & $F 4$ \\
(MW) & & & & \\
\hline-1500 & 0.000 & 0.000 & 0.000 & 0.000 \\
-1450 & 0.000 & 0.000 & 0.000 & 0.000 \\
-1400 & 0.000 & 0.000 & 0.000 & 0.000 \\
-1350 & 0.000 & 0.000 & 0.000 & 0.000 \\
-1300 & 0.000 & 0.000 & 0.000 & 0.000 \\
-1250 & 0.000 & 0.000 & 0.000 & 0.000 \\
-1200 & 0.000 & 0.000 & 0.071 & 0.000 \\
-1150 & 0.000 & 0.000 & 0.099 & 0.000 \\
-1100 & 0.000 & 0.000 & 0.187 & 0.000 \\
-1050 & 0.000 & 0.000 & 0.218 & 0.000 \\
-1000 & 0.000 & 0.000 & 0.303 & 0.000 \\
-950 & 0.000 & 0.000 & 0.337 & 0.000 \\
-900 & 0.000 & 0.000 & 0.419 & 0.000 \\
-850 & 0.000 & 0.000 & 0.455 & 0.000 \\
-800 & 0.000 & 0.099 & 0.535 & 0.000 \\
-750 & 0.000 & 0.218 & 0.574 & 0.000 \\
-700 & 0.000 & 0.337 & 0.651 & 0.000 \\
-650 & 0.000 & 0.455 & 0.693 & 0.000 \\
-600 & 0.000 & 0.574 & 0.768 & 0.000 \\
-550 & 0.000 & 0.693 & 0.812 & 0.040 \\
-500 & 0.000 & 0.812 & 0.884 & 0.200 \\
-450 & 0.000 & 0.931 & 0.931 & 0.360 \\
-400 & 0.071 & 0.951 & 0.951 & 0.520 \\
-350 & 0.187 & 0.832 & 0.884 & 0.680 \\
-300 & 0.303 & 0.713 & 0.832 & 0.840 \\
-250 & 0.419 & 0.594 & 0.768 & 1.000 \\
-200 & 0.535 & 0.475 & 0.713 & 0.840 \\
-150 & 0.651 & 0.356 & 0.651 & 0.680 \\
-100 & 0.768 & 0.238 & 0.594 & 0.520 \\
-50 & 0.884 & 0.119 & 0.535 & 0.360 \\
0 & 1.000 & 0.000 & 0.475 & 0.200 \\
50 & 0.884 & 0.000 & 0.419 & 0.040 \\
100 & 0.768 & 0.000 & 0.356 & 0.000 \\
150 & 0.651 & 0.000 & 0.303 & 0.000 \\
200 & 0.535 & 0.000 & 0.238 & 0.000 \\
250 & 0.419 & 0.000 & 0.187 & 0.000 \\
300 & 0.303 & 0.000 & 0.119 & 0.000 \\
350 & 0.187 & 0.000 & 0.071 & 0.000 \\
400 & 0.071 & 0.000 & 0.000 & 0.000 \\
450 & 0.000 & 0.000 & 0.000 & 0.000 \\
500 & 0.000 & 0.000 & 0.000 & 0.000 \\
\hline & & & & \\
& & & &
\end{tabular}

two approaches will yield different values of $\Delta L_{p \text { desired }}$. In this paper, the equal-area algorithm is adopted since different weighting factors $W$ can be put on the operator's recommendation, making the method more flexible than the minimum-maximum method.

Using the updated peak load $(-300 \mathrm{MW}$ $+11113.87 \mathrm{MW}=10813.87 \mathrm{MW}$ ), the forecast hourly loads as shown in Table 4 can be reached. By comparing the results in Table 2 and Table 4, it can be seen that the error in peak load has been reduced from $2.45 \%$ to $0.32 \%$. In addition the MAE is reduced from $1.89 \%$ to $0.63 \%$ by using the fuzzy expert system for peak-load updating.

Table 4: Forecast hourly loads from the fuzzy expert system using updated peak load

\begin{tabular}{rcrrr}
\hline Hour & $\begin{array}{l}\text { Actual } \\
\text { loads (MW) }\end{array}$ & \multicolumn{1}{c}{$\begin{array}{c}\text { Forecast } \\
\text { loads (MW) }\end{array}$} & Error (MW) & Error $(\%)$ \\
\hline 1 & 7589.00 & 7589.39 & -0.39 & $-3.61 \mathrm{E}-05$ \\
2 & 7277.00 & 7304.60 & -27.60 & $-2.54 \mathrm{E}-03$ \\
3 & 7101.00 & 7104.00 & -3.01 & $-2.77 \mathrm{E}-04$ \\
4 & 6892.00 & 6952.93 & -60.93 & $-5.62 \mathrm{E}-03$ \\
5 & 6763.00 & 6830.42 & -67.42 & $-6.21 \mathrm{E}-03$ \\
6 & 6681.00 & 6778.23 & -97.23 & $-8.96 \mathrm{E}-03$ \\
7 & 6670.00 & 6767.99 & -97.99 & $-9.03 \mathrm{E}-03$ \\
8 & 7242.00 & 7342.82 & -100.82 & $-9.29 \mathrm{E}-03$ \\
9 & 9333.00 & 9283.64 & 49.36 & $4.55 \mathrm{E}-03$ \\
10 & 10068.00 & 9942.62 & 125.38 & $1.16 \mathrm{E}-02$ \\
11 & 10393.00 & 10403.58 & -10.58 & $-9.75 \mathrm{E}-04$ \\
12 & 10483.00 & 10523.30 & -40.30 & $-3.72 \mathrm{E}-03$ \\
13 & 9384.00 & 9386.78 & -2.78 & $-2.56 \mathrm{E}-04$ \\
14 & 10710.00 & 10635.13 & 74.87 & $6.90 \mathrm{E}-03$ \\
15 & 10848.00 & 10813.87 & 34.13 & $3.15 \mathrm{E}-03$ \\
16 & 10658.00 & 10671.70 & -13.70 & $-1.26 \mathrm{E}-03$ \\
17 & 10421.00 & 10509.84 & -88.84 & $-8.19 \mathrm{E}-03$ \\
18 & 9587.00 & 9720.21 & -133.21 & $-1.23 \mathrm{E}-02$ \\
19 & 9576.00 & 9620.75 & -44.75 & $-4.12 \mathrm{E}-03$ \\
20 & 9822.00 & 9889.73 & -67.73 & $-6.24 \mathrm{E}-03$ \\
21 & 9538.00 & 9662.84 & -124.84 & $-1.15 \mathrm{E}-02$ \\
22 & 9037.00 & 9184.76 & -147.76 & $-1.36 \mathrm{E}-02$ \\
23 & 8696.00 & 8825.38 & -129.38 & $-1.19 \mathrm{E}-02$ \\
24 & 8221.00 & 8316.00 & -95.00 & $-8.76 \mathrm{E}-03$ \\
\hline
\end{tabular}

MAE $=0.63 \%, \quad \mathrm{RMSE}=0.75 \%$, forecast peak $=10813.87 \mathrm{MW}$, actual peak $=10848 \mathrm{MW}$, error $=-34.13 \mathrm{MW}(0.32 \%)$, forecast trough $=6767.99 \mathrm{MW}$, actual trough $=6670 \mathrm{MW}$, error $=$ $-97.99 \mathrm{MW}(-0.90 \%)$

To improve the accuracy of the forecast hourly loads further, the trough load can also be updated by using the fuzzy expert system in exactly the same way as that for peak-load updating except that low temperature $T_{t}$ should be used instead of high temperature $T_{p}$. The

Table 5: Forecast hourly loads from the fuzzy expert system using updated peak load and trough loads

\begin{tabular}{rrrrr}
\hline Hour & \multicolumn{1}{l}{$\begin{array}{l}\text { Actual } \\
\text { loads }(\mathrm{MW})\end{array}$} & $\begin{array}{l}\text { Forecast } \\
\text { loads }(\mathrm{MW})\end{array}$ & Error $(\mathrm{MW})$ & \multicolumn{1}{l}{ Error $(\%)$} \\
\hline 1 & 7589.00 & 7510.32 & 78.68 & $7.25 \mathrm{E}-03$ \\
2 & 7277.00 & 7218.54 & 58.46 & $5.39 \mathrm{E}-03$ \\
3 & 7101.00 & 7013.03 & 87.97 & $8.11 \mathrm{E}-03$ \\
4 & 6892.00 & 6858.25 & 33.75 & $3.11 \mathrm{E}-03$ \\
5 & 6763.00 & 6732.73 & 30.27 & $2.79 \mathrm{E}-03$ \\
6 & 6681.00 & 6679.26 & 1.74 & $1.60 \mathrm{E}-04$ \\
7 & 6670.00 & 6668.77 & 1.23 & $1.14 \mathrm{E}-04$ \\
8 & 7242.00 & 7257.70 & -15.70 & $-1.45 \mathrm{E}-03$ \\
9 & 9333.00 & 9246.11 & 86.89 & $8.01 \mathrm{E}-03$ \\
10 & 10068.00 & 9921.26 & 146.74 & $1.35 \mathrm{E}-02$ \\
11 & 10393.00 & 10393.52 & -0.52 & $-4.79 \mathrm{E}-05$ \\
12 & 10483.00 & 10516.18 & -33.18 & $-3.06 \mathrm{E}-03$ \\
13 & 9384.00 & 9351.78 & 32.22 & $2.97 \mathrm{E}-03$ \\
14 & 10710.00 & 10630.75 & 79.25 & $7.31 \mathrm{E}-03$ \\
15 & 10848.00 & 10813.87 & 34.13 & $3.15 \mathrm{E}-03$ \\
16 & 10658.00 & 10668.21 & -10.21 & $-9.41 \mathrm{E}-04$ \\
17 & 10421.00 & 10502.38 & -81.38 & $-7.50 \mathrm{E}-03$ \\
18 & 9587.00 & 9693.39 & -106.39 & $-9.81 \mathrm{E}-03$ \\
19 & 9576.00 & 9591.49 & -15.49 & $-1.43 \mathrm{E}-03$ \\
20 & 9822.00 & 9867.06 & -45.06 & $-4.15 \mathrm{E}-03$ \\
21 & 9538.00 & 9634.62 & -96.62 & $-8.91 \mathrm{E}-03$ \\
22 & 9037.00 & 9144.81 & -107.81 & $-9.94 \mathrm{E}-03$ \\
23 & 8696.00 & 8776.62 & -80.62 & $-7.43 \mathrm{E}-03$ \\
24 & 8221.00 & 8254.75 & -33.75 & $-3.11 \mathrm{E}-03$ \\
\hline $\mathrm{MAE}$ & $0.50 \%$ & $\mathrm{R}$ & & \\
\hline
\end{tabular}

$\mathrm{MAE}=0.50 \%, \quad \mathrm{RMSE}=0.62 \%$, forecast peak $=10813.87 \mathrm{MW}$ actual peak $=10848 \mathrm{MW}$, error $=34.13 \mathrm{MW} \quad(0.32 \%)$, forecast trough $=6668.77 \mathrm{MW}$, actual trough $=6670 \mathrm{MW}$, error $=1.23 \mathrm{MW}$ $(0.01 \%)$ 
detailed procedures and membership functions for trough-load update are not presented owing to limits on space. The final forecast loads are listed in Table 5. By comparing the results in Table 4 and Table 5, it is found that the error in trough load has been reduced from $0.9 \%$ to $0.01 \%$ while the MAE is reduced from $0.63 \%$ to $0.5 \%$. It is concluded that through the updating of peak load and trough load, the accuracy of the forecast hourly loads can be significantly improved by the proposed fuzzy expert system.

\section{Conclusions}

A fuzzy expert system has been designed for short-term load forecasting. The uncertainties in weather variables and statistical model are taken into account by using the fuzzy set theory. The operator's heuristic rules are also incorporated into the system. Two approaches based on the minimum-maximum algorithm and the equal-area algorithm are proposed to determine the most desirable change in peak (trough) load from separate sources of fuzzy information. The accuracy of the forecast hourly loads can be significantly improved after the peak load and trough load are updated by the fuzzy expert system. The designed fuzzy expert system has been successfully applied to forecast the hourly loads of the Taiwan Power Company.

\section{References}

1 GROSS, G., and GALIANA, F.D.: 'Short term load forecasting', Proc. IEEE, 1987, 75, pp. 1558-1573

2 CHRISTIAANSE, W.R.: 'Short-term load forecasting using general exponential smoothing', IEEE Trans., 1971, PAS-90, pp. 900-911
3 DAVEY, J, SOACHS, J J, CUNNINGHAM, G.W., and PRIEST, K.W.: 'Practical application of weather sensitive load forecasting to system planning', IEEE Trans., 1972, PAS-91, pp. 917-977

4 THOMPSON, R.P.: 'Weather sensitive demand and energy analysis on a large geographically diverse power system-application to shortterm hourly electric demand forecasting', IEEE Trans., 1976, PAS-95, pp. 384-393

5 PAPALEXOPOULOS, A.D., and HESTERBERG, T.C.: 'A regression-based approach to short-term system load forecasting'. Proceedings of 1989 PICA Conference, pp. 414-423

6 MESLIER, F.: 'New advances in short term load forecasting using Box and Jenkins approach'. Paper A78 051-5, IEEE/PES Winter Meeting, 1978

7 IRISARRI, G.D., WIDERGREN, S.E., and YEHSAKUL, P.D.; 'On-line load forecasting for energy control center application', IEEE Trans., 1982, PAS-101, pp. 71-78

8 RAHMAN, S, and BHATNAGAR, R. 'An expert system based algorithm for short term load forecast', IEEE Trans., 1988, PWRS-3, pp. 392-399

9 JABBOUR, K., RIVEROS, J.F.V., LANDSBERGEN, D., and MEYER, W.: 'ALFA: automated load forecasting assistant', IEEE Trans., 1988, PWRS-3, pp. 908-914

10 HO, K.L., HSU, Y.Y., CHEN, C.F., LEE, T.E., LIANG, C.C., LAI, T.S., and CHEN, K.K.: 'Short term load forecasting of Taiwan power system using a knowledge-based expert system', IEEE Trans., PWRS-5, pp. 1214-1221

11 BUCHANAN, B.G., and SHORTLIFFE, E.H.: 'Rule-based expert systems' (Addison-Wesley, 1984), chapter 11

12 SHAFER, G.: 'A mathematical theory of evidence' (Princeton University Press, 1976)

13 ZIMMERMANN, H.J.: 'Fuzzy set theory and its applications' (Kluwer-Nijhoff Publishing, 1985)

14 ZADEH, LA.: "The role of fuzzy logic in the management of uncertainty in expert systems', in Fuzzy sets and systems', 1983, pp. 199227

15 MAMDANI, E.H., OSTERGAARD, J.J., and LEMBESSIS, E.: 'Use of fuzzy logic for implementing rule-based control of industrial processes'. TIMS/Studies in the Management Sciences 20, 1984, pp. $429-445$ 